\title{
Multi-Input Ćuk Inverter Based on Model Predictive Control
}

\author{
Mohamed A. Ismeil \\ (https://orcid.org/0000-0002-9885-8501)
}

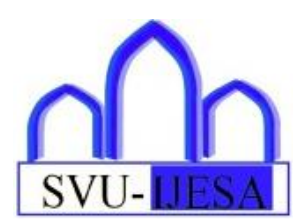

\begin{abstract}
In this paper multi-input Ćuk- derived buckboost inverter is presented based on Model Predictive Control (MPC). The control technique is applied to multiinput Cuk- derived buck-boost inverter because of the several features such as reduction of passive elements compared with two-stage topologies and the family of impedance inverters such as Z-source Inverter (ZSI), Quazi Source Inverter (QSI), T-Source Inverter (TSI), and YSource Inverter (YSI). In addition, it is suitable for photovoltaic applications as it has the ability to boost the $\mathrm{DC}$ voltage from the PV cells and also invert it to AC voltage in one stage. The model predictive control is applied in this paper to get a high response in the dynamic changes. In addition, more than one variable can be controlled in the same cost function, all the aforementioned features of the MPC can be achieved by using a technical called reducing horizon technique. As the actual values are measured and compared with the reference for several solutions, the less accurate error will be given to use as an action for the switched control. The power topology circuit and control algorithm have been validated by MATLAB/SIMULINK Software.
\end{abstract}

Keywords: SEPIC buck-boost converter; Ćuk buck-boost converter; Two-Stage Inverter; Model Predictive Control; multi-input inverter.

\section{Introduction}

\footnotetext{
Received: 17 April 2021/ Accepted: 2 May 2021

$\square$ Corresponding Author: Mohamed Ismeil, mohamedismeil@eng.svu.edu.eg

Electrical Engineering Department Faculty of Engineering, South Valley University Qena, Egypt.
}

It has become necessary to develop and use types of energies, the main feature of which is that it is renewable. The use of wind and solar energy has a great impact towards changing the orientation of nations [1-3], and the use and development of this type of energy has become national security and an important strategy towards development. Due to the use of this type of energies, researchers and the industry had a great deal of development in the process of interfacing between these energies and the electrical grid or different AC/DC loads. These methods varied, as the first solution was to use two-stage $[4,5]$, the first stage from DC to DC with the possibility of boosting and the second stage for inverting from $\mathrm{DC}$ to $\mathrm{AC}$, but the high cost and the increase in the number of circuit components used were the most important reasons for using the second solution, which is to use only single stage that works the two functions, which is the DC-DC and DC-AC. The initial view of using this model of connection was by gathering a large number of photovoltaic cells in series, and this was exposed to many problems, especially when the group was exposed to shadows [6-8].

The presentation of the impedance inverter family led to a change in the philosophy of the one-stage, as it dispensed with the stage of boosting using DC-DC and was enlarged by adding the ninth case in the operation of the switches and using passive elements (two capacitors and two indictors) in front of the inverter [9]. The researchers introduced a lot of improvement to this inverter, whether in the power circuit or the control circuit, to overcome the problems it faces such as small boosting, large stresses on the switches, and inrush current [10-13]. Despite the many advantages of 
impedance inverter, the number of components it needs, in operation, lost several of its strengths, as well as adding a ninth case to control the operation switches, which complicated the control.

A split inverter was introduced as an effective alternative to the impedance inverter as it contains fewer components and does not require a ninth case to control the switches [14-16]. It is worth noting that the use of three diodes in split inverter led to an increase in the conduction losses and although this problem was addressed by replacing the diodes with switches [17], it increased the complications of the control and the losses of the switching increased due to using of high frequencies.

From another perspective, the achievement of the bidirectional buck-boost power conversion, the buck-boost circuits derived from Ćuk and SEPIC buck-boost converter have been proposed in [18], besides, smaller passive components can be used compared with previous topologies [18]. The general illustration of the Ćuk and SEPIC buck-boost converter is shown in Fig. 1.

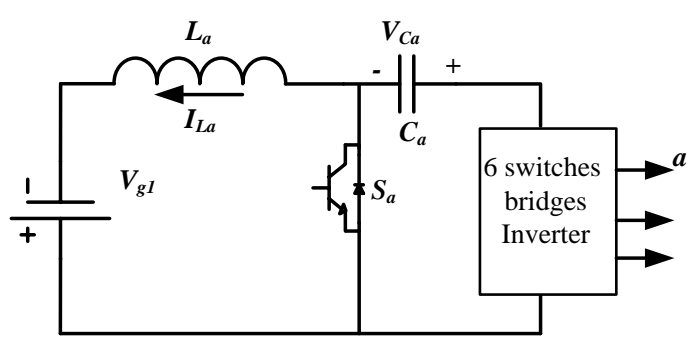

a)

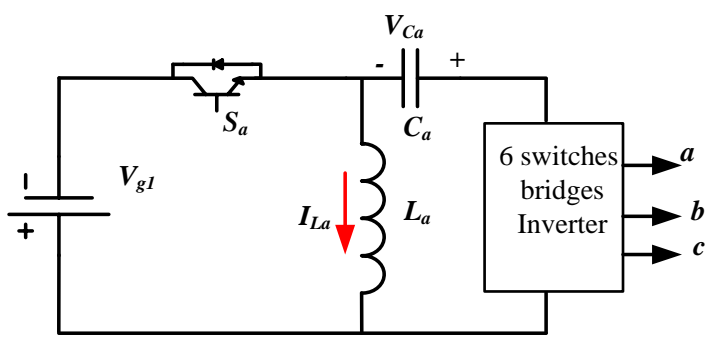

b)

Fig. 1 illustration of the a) Ćuk buck-boost converter

b) SEPIC buck-boost converter

in [18] a lot of configurations have been presented to use the SEPIC and Ćuk buck-boost converter as inverter but they suffers from the unbalanced three-phase output voltage because the third leg is not connected to the inverter point. For this reason, In particular, the B6 inverter with six switches in the three-phase inverter circuitry can satisfy most low or medium voltage applications such as motor drive or renewable energy conversion. It was modified to achieve boosting with using Ćuk derived buck-boost B6
Inverter [18].

This solution has become very suitable for use in photovoltaic applications especially when the output voltage of the photovoltaic modules is small.

The phenomenon of shadows has become a big problem facing all photovoltaic plants. In [19] an excellent solution to this problem has been presented, using Multi-Input Ćuk Inverter, where all inputs are PV and each Input has its own Maximum Powe Point Tracking (MPPT) as shown in Fig. 2. in addition, the topology presented has lower passive elements compared to the Z-source inverter and split source inverter

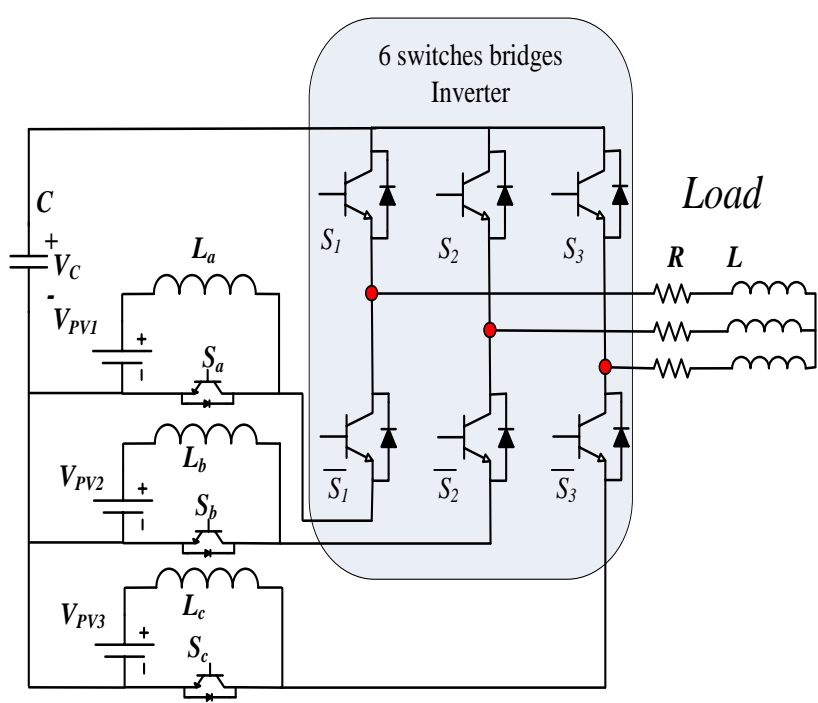

Fig. 2 Multi-Input Ćuk- derived buck-boost inverter [19].

The Model Predictive Control (MPC) has been presented included with several advantages, including the high speed of response to dynamic changes, non-minimal value, and it is easy to expand for multi-variable systems. In this paper, the control of the Multi-Input Ćuk Inverter is modified to be with predictive control and using DC source to achieve the concept of using predictive control for the Multi-Input Ćuk.

\section{Modeling of Multi-Input Ćuk- derived buck-boost inverter}

The system consists of three separate power supply circuits for each leg of the six switches inverter. Each circuit has one power supply, one inductor, and one active switch, the capacitor is connected between the active point of the six switches inverter and the second point with the negative point of the power supply. 


\subsection{Load currents modeling}

The output load current can be represented by considering the states of the six switches inverter which are 6 active state $\left(\mathrm{V}_{1}\right.$ to $\left.\mathrm{V}_{6}\right)$ and two zero states $\left(\mathrm{V}_{0}, \mathrm{~V}_{7}\right)$ The value of each output voltage state is listed in Table 1

Table 1 The vector values of output voltage

\begin{tabular}{|c|c|}
\hline Output Voltage $\left(V_{\alpha}+J V_{\beta}\right)$ & $\begin{array}{c}\text { Switching State } \\
S=\left[\begin{array}{l}S_{1} S_{2} S_{3} S_{4} S_{5} S_{6} S_{a} S_{b} S_{c}\end{array}\right]\end{array}$ \\
\hline$V_{0}=0$ & {$\left[\begin{array}{llllllllll}0 & 0 & 0 & 1 & 1 & 1 & 1 & 1 & 1\end{array}\right]$} \\
\hline$V_{1}=\frac{2}{3} \cdot V_{d c}$ & {$\left[\begin{array}{lllllllll}1 & 0 & 0 & 0 & 1 & 1 & 1 & 1 & 1\end{array}\right]$} \\
\hline$V_{2}=\frac{1}{3} \cdot V_{d c}+j \cdot \frac{\sqrt{3}}{3} \cdot V_{d c}$ & {$\left[\begin{array}{lllllllll}1 & 1 & 0 & 0 & 0 & 1 & 1 & 1 & 1\end{array}\right]$} \\
\hline$V_{3}=-\frac{1}{3} \cdot V_{d c}+j \cdot \frac{\sqrt{3}}{3} \cdot V_{d c}$ & {$\left[\begin{array}{llllllllll}0 & 1 & 0 & 1 & 0 & 1 & 1 & 1 & 1\end{array}\right]$} \\
\hline$V_{4}=-\frac{2}{3} \cdot V_{d c}$ & {$\left[\begin{array}{llllllllll}0 & 1 & 1 & 1 & 0 & 0 & 1 & 1 & 1\end{array}\right]$} \\
\hline$V_{5}=-\frac{1}{3} \cdot V_{d c}-j \cdot \frac{\sqrt{3}}{3} \cdot V_{d c}$ & {$\left[\begin{array}{llllllllll}0 & 0 & 1 & 1 & 1 & 0 & 1 & 1 & 1\end{array}\right]$} \\
\hline$V_{6}=\frac{1}{3} \cdot V_{d c}-j \cdot \frac{\sqrt{3}}{3} \cdot V_{d c}$ & {$\left[\begin{array}{lllllllll}1 & 0 & 1 & 0 & 1 & 0 & 1 & 1 & 1\end{array}\right]$} \\
\hline$V_{7}=0$ & {$\left[\begin{array}{llllllll}1 & 1 & 1 & 0 & 0 & 0 & 0 & 0\end{array}\right]$} \\
\hline
\end{tabular}

The predicted value of output load current $i_{o}(k+1)$ can be represented as

$$
i_{o}(k+1)=\frac{T_{s} \cdot V_{x}(k+1)+L \cdot i_{o}(k)}{L+R \cdot T_{S}}
$$

where, $V_{x}(k+1)$ is the output voltage at the state $\mathrm{x}$ where $\mathrm{x}$ change from 0 to 7 , the sampling time is $T_{s}$, $\mathrm{L}$ is load inductance, $\mathrm{R}$ is the load resistance.

2.2 The modeling of Inductor Current and Capacitor Voltage in the Multi-Input Ćuk

Regarding to single input Ćuk, there are two modes, the first mode when the inductor charging, This mode appears when $s_{a}$ is turned on as shown in Fig 3a

The current and voltage in this mode can be represented as:

$$
L_{a} \frac{\mathrm{d} i_{L a}}{d t}=V_{g} \quad, \quad \mathrm{Ca} \frac{\mathrm{d} v_{c a}}{d t}=i_{\text {instant }}
$$

Where $L_{1}$ is the inductance of the input inductor, $C$ is the capacitance of the DC link. Where $i_{\text {instant }}$ is the instant value of the output currents of $I_{a}, I_{b}$, and $I_{c}$.

The second mode appears when the upper switches in the six switches inverter are turned on and the pass of inductor current pass through the antiparallel diodes of the lower switches, the inductor discharging as shown in Fig. 3b. The capacitor voltage and inductor current as follows:

$$
\mathrm{Ca} \frac{\mathrm{d} v_{c a}}{d t}=i_{\text {instant }}-i_{L a}, \quad L_{a} \frac{\mathrm{d} i_{L a}}{d t}=v_{g}-v_{c a}
$$

Equation (2) can be represented as a discrete time model

for future inductor current and future capacitor voltage as follows:

$\left\{\begin{array}{c}i_{L a}(k+1)=i_{L a}(k)+\frac{T_{s}}{L_{a}}\left(v_{g}(k)\right) \\ v_{c a}(k+1)=v_{c a}(k)+\frac{T_{s}}{C_{a}} i_{\text {instant }}(k)\end{array}\right.$

The same action can be applied on equation (3) for the discrete-time model for the predict inductor current and capacitor voltage as:

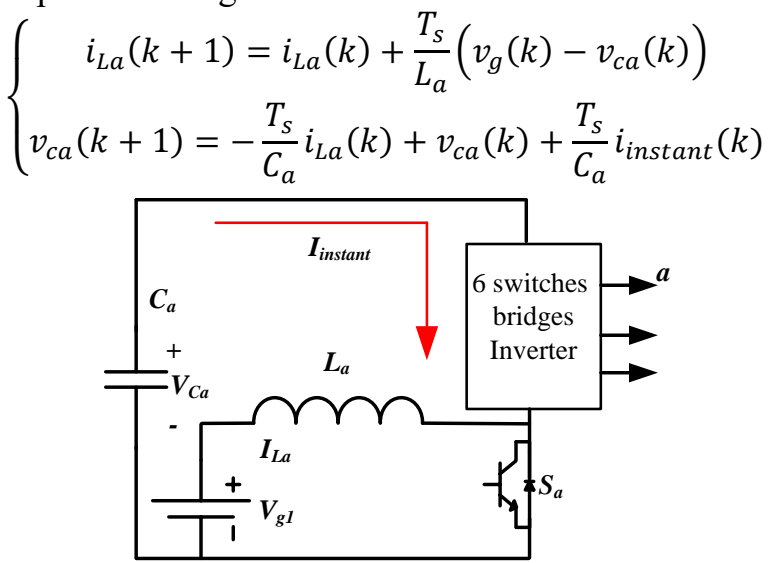

(a)

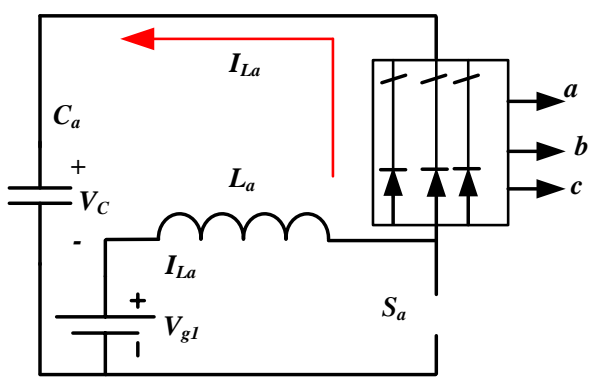

(b)

Fig. 3 the two cases Inverter circuits: a) charging mode

b) discharging mode

\subsection{Cost Function Minimization}

The cost function $\mathrm{g}(i)$ is defined as the absolute error between the predicted values and the references values the weight of each error defines the priority importance by inserting the weigh factor $\lambda$ in the cost function which can be calculated as :

$$
\begin{aligned}
g(i)=\lambda_{\text {io }}\left(\mid i_{o_{\text {ref }}}\right. & \left.(k+1)-i_{o}(k+1) \mid+\right) \\
& +\lambda_{v c a}\left|v_{C a_{r e f}}(k+1)-v_{C a}(k+1)\right| \\
& ++\lambda_{i_{L a}}\left|i_{L a_{r e f}}(k+1)-i_{L a}(k+1)\right|
\end{aligned}
$$

Where $i_{o_{\text {ref }}}(k+1)$ the reference output current, and 
$v_{\text {Ca_ref }}(k+1)$ is the capacitor reference voltage. $i_{L a_{r e f}}(k+1) \quad$ is the inductor reference current. Also, $\lambda_{i L a}$ the weighting factor of the input inductor current, $\lambda_{v c a}$ weighting factor capacitor voltage and $\lambda_{i o}$ the inductor output current.

As shown from Fig. 4 the proposed control system control the output currents, input capacitor, and inductor current by using four current sensors and one voltage sensor.

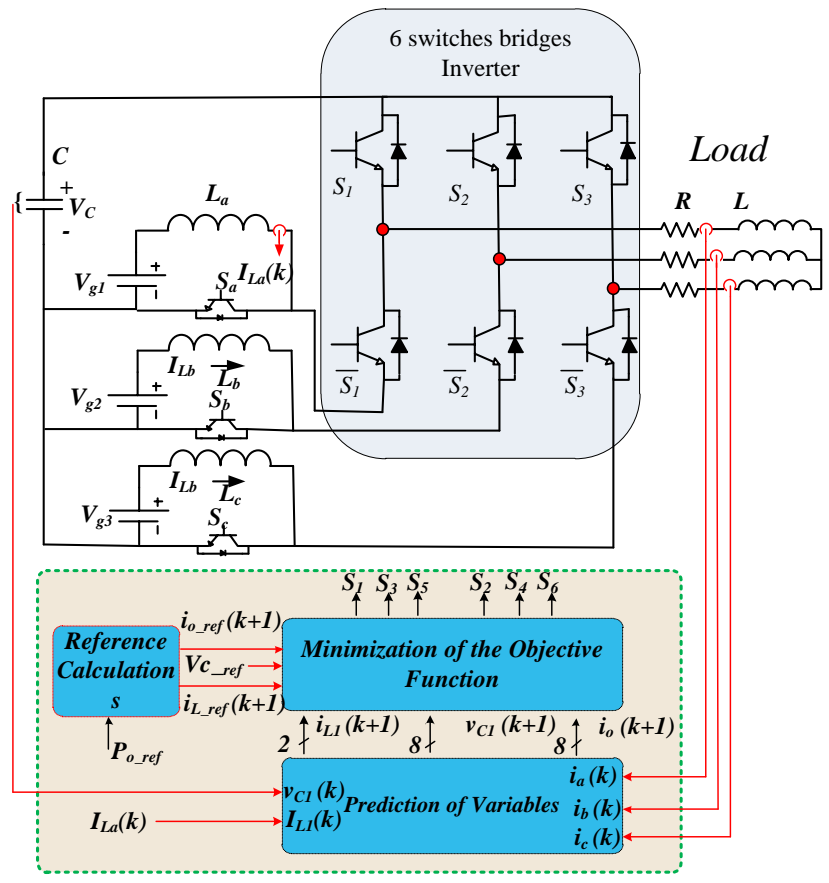

Fig. 4 Total system with Block control diagram of Multi-Input Ćuk- derived buck-boost inverter.

\section{Simulation results}

MATLAB/SIMULINK software is used to validate the proposed control system based on MPC.

The parameter of simulation is listed in Table 2

Table 2 Simulation parameters

\begin{tabular}{lcr}
\hline Parameter & Symbol & Value \\
\hline Input voltage & $V_{g l}=V_{g 2}=V_{g 3}$ & $100 \mathrm{~V}$ \\
Ćuk inductance & $L_{a}=L_{b}=L_{c}$ & $3000 \mu \mathrm{H}$ \\
Ćuk capacitance & $C_{a}$ & $470 \mu \mathrm{F}$ \\
Resistance of load & $R$ & $10 \Omega / \mathrm{phase}$ \\
Inductance of load & $L$ & $5 \mathrm{mH} /$ phase \\
Sampling Time & $T_{s}$ & $100 \mu \mathrm{Sec}$ \\
\hline
\end{tabular}

The proposed control technique has been validated via change the load from $1.5 \mathrm{~A}$ to $4 \mathrm{~A}$ at $0.5 \mathrm{sec}$ through the R-L load. As shown in Fig 5 the actual current follows with high accuracy and fast response the reference one. in addition, the period of the dynamic change is presented in zoom window in Fig. 4,

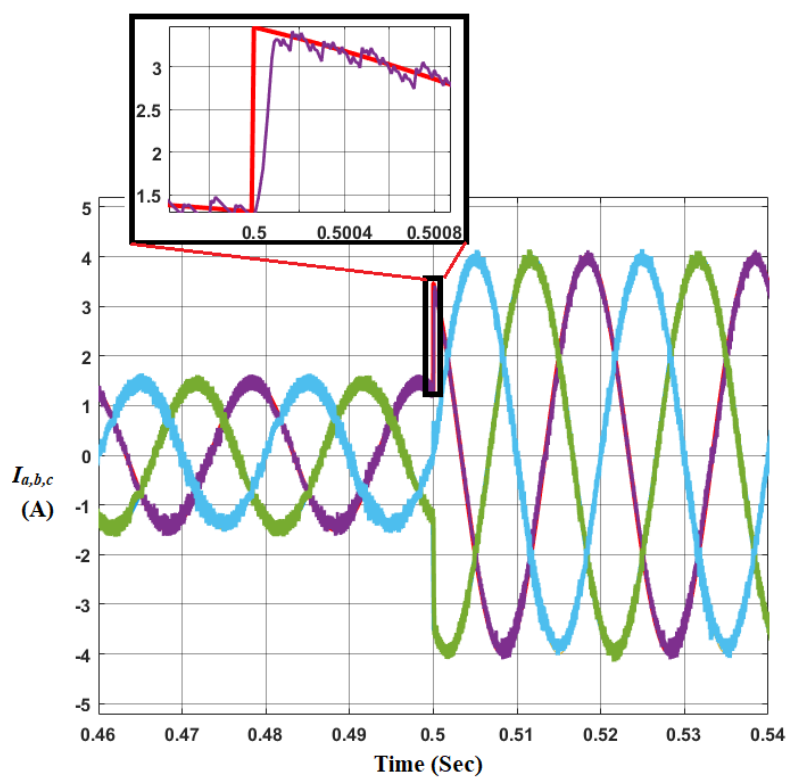

Fig. 5 output currents with step change

The line voltage and phase voltage have presented in Fig. 6 the line voltage alternate between $-300 \mathrm{~V}$ and $+300 \mathrm{~V}$, also the phase voltage alternate between $-200 \mathrm{~V}$ and $+200 \mathrm{~V}$.

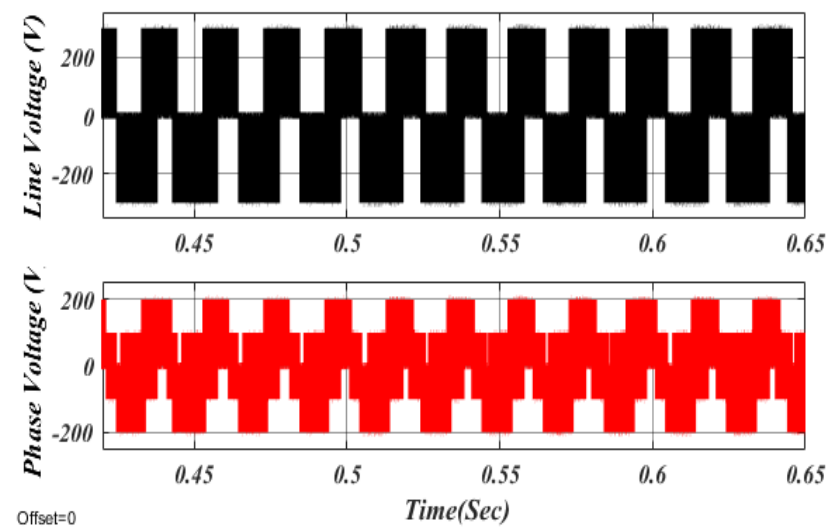

Fig. 6 Line voltage and phase voltage for of Multi-Input Ćukderived buck-boost inverter.

The control role is to maintain the value of capacitance voltage at a certain reference value which is $300 \mathrm{~V}$. it clear presented in Fig. 7. The main advantage of MPC is shown with high response to change and very low under/over shoot value. It worth noting that the over-shoot value is decreased to reach a very small value $(0.1133 \%)$ from the actual value. 


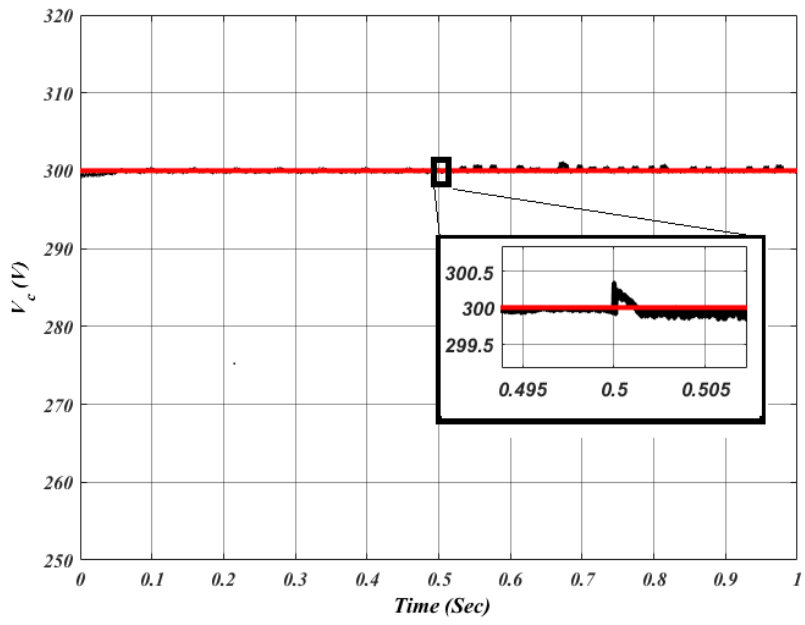

Fig. 7 Dynamic response of capacitor voltage

As shown in equation (6) the cost function contains three variables one of them is the inductor current. It has been chosen to be controlled to maintain the input current at a certain value and the value of its inductance $\left(L_{a}\right)$ is chosen to make the inductor current in Continuous Current Mode (CCM)

The actual inductor current and its reference are shown in Fig. 7 which the step from $0.415 \mathrm{~A}$ to $1.0889 \mathrm{~A}$

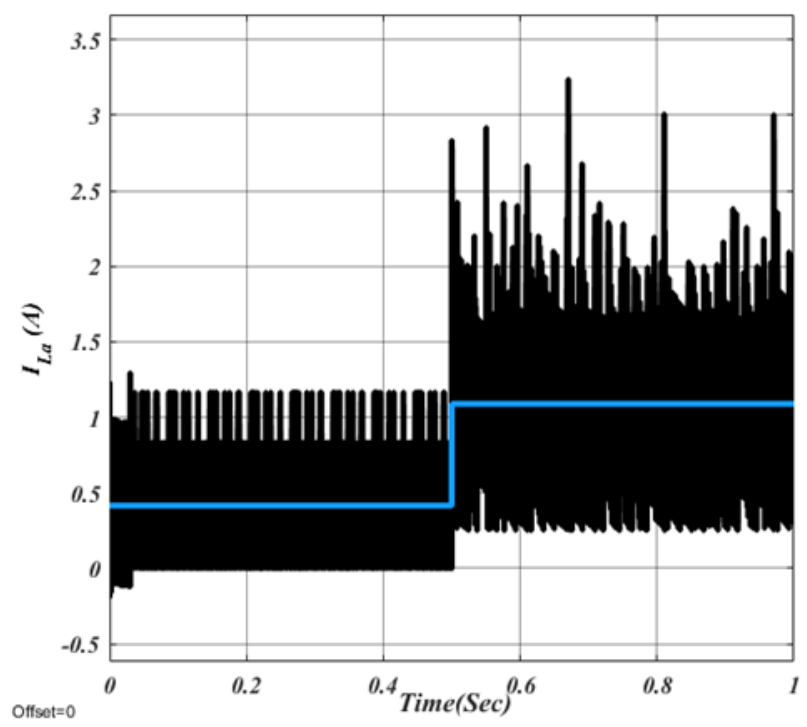

Fig. 8 Dynamic response of inductor current

\section{Conclusion}

In this paper Multi-Input Ćuk- derived buck-boost inverter based on MPC has been presented. Three variables have been controlled with MPC. The results is clear present the power of using MPC in fast-tracking the dynamic change in the controlled variables. Also, the overshoot value due to dynamic change is decreased to reach a very small value $(0.1133 \%)$ of the actual value

\section{Future Work}

- Using PV and using the MPC to solve the shading problem.

- Modified the MPC algorithm to minimize the ripple value in the inductor's currents.

- Using online optimization to adaptive the best values of weighing factor in the cost function.

\section{References}

[1] Jianglong Li, Chuanwang Sun "Towards a low carbon economy by removing fossil fuel subsidies? "China Econ Rev, 50 (August 2018), pp. 17-33

[2] M. Dahmane, J. Bosche, A. El-Hajjaji and M. Dafarivar, "Renewable energy management algorithm for stand-alone system," 2013 International Conference on Renewable Energy Research and Applications (ICRERA), 2013, pp. 621-626.

[3] Fulekar, M. H. Environmental biotechnology. CRC Press, 2010.

[4] N. Gloire, Dong Lei, Liao Xiaozhong and Xiao Furong, "Single phase grid-connected PV inverter applying a boost coupled inductor," 2014 IEEE Conference and Expo Transportation Electrification Asia-Pacific (ITEC Asia-Pacific), 2014, pp. 1-5, doi: 10.1109/ITEC-AP.2014.6941023.

[5] M. Shayestegan, "Overview of grid-connected two-stage transformer-less inverter design". Journal of Modern Power Systems and Clean Energy 2018, 6.4: 642-655.

[6] H., Gaubert, J. P., Ivanovici, T., Champenois, G., \& Andrei” Modeling of the photovoltaic cell circuit parameters for optimum connection model and real-time emulator with partial shadow conditions" Energy, 2012, 42.1: 57-67.

[7] Q. Zhang, X. Sun, Y. Zhong, and M. Matsui, "A novel topology for solving the partial shading problem in photovoltaic power generation system." In: 2009 IEEE 6th International Power Electronics and Motion Control Conference. IEEE, 2009. p. 2130-2135.

[8] Z. Liying,M. Liang, L. Zhigang, C. Mingxuan,and \& W. Jianwen, "Implementation and simulation analysis of GMPPT algorithm under partial shadow condition". Energy Procedia, 2019, 158: 418-423.

[9] Y. P. Siwakoti, F. Z. Peng, F. Blaabjerg, P. C. Loh, G. E. Town, "Impedance source networks for electric power conversion part I. A topological review", IEEE Trans. Power Electron., vol. 30, no. 2, pp. 699-716, Apr. 2015.

[10] M. Ismeil, R. Kennel, and H. Abu-Rub. "Modeling and Experimental Study of Three-phase Improved Switched Inductor Z-Source Inverter." EPE Journal 24.4 (2014): 14-27.

[11] Mohamed A. Ismeil, Mohamed Orabi, Ralph Kennel, Haitham Abu-Rub." Modeling and Experimental Study of Three-phase Improved Switched Inductor Z-Source Inverter" EPE Journal Vol 24, no. 4 pp 14-27 Dec. 2014

[12] D. Vinnikov and I. Roasto, "Quasi-z-source-based isolated dc/dc converters for distributed power generation," Industrial Electronics, IEEE Transactions on, vol. 58, no. 1, pp. 192-201, Jan 2011. 
[13] Abualkasim Bakeer, Mohamed A. Ismeil, and Mohamed Orabi" Modified Finite Control Set-Model Predictive Controller (MFCS-MPC) for quasi Z-Source Inverters based on a Current Observer" Journal of Power Electronics, Vol. 17, No. 3, pp. 610620, May 2017

[14] A. Abdelhakim, P. Mattavelli, and G. Spiazzi. "Split-source inverter." In IECON 2015-41st Annual Conference of the IEEE Industrial Electronics Society, pp. 001288-001293. IEEE, 2015.

[15] P. Yadav, A. K. Sharma and S. Garg "Performance Analysis of Three-Phase Split Source Inverter." In 2016 International Conference on Micro-Electronics and Telecommunication Engineering (ICMETE), pp. 504-507. IEEE, 2016.
[16] Mohamed A Ismeil “ High Dynamic Performance for Split-Source Inverter based on Finite Control Set Model Predictive Control" 21st International Middle East Power Systems Conference (MEPCON) IEEE, 2019.

[17] Lee, Sze Sing, and Yeh En Heng. "Improved single-phase splitsource inverter with hybrid quasi-sinusoidal and constant PWM." IEEE Transactions on industrial electronics 64.3 (2016): 2024-2031.

[18] F. Gao, P.C Loh, R.F Blaabjerg, D. Teodorescu, M. Vilathgamuwa, "Component-minimized buck-boost voltage source inverters. In Proceedings of the 2007 IEEE Industry Applications Annual Meeting, New Orleans, LA, USA, 23-27 September 2007; pp. 23112318. 